\title{
A fibril-specific, conformation-dependent antibody recognizes a subset of $A \beta$ plaques in Alzheimer disease, Down syndrome and Tg2576 transgenic mouse brain
}

\author{
Floyd Sarsoza · Tommy Saing · Rakez Kayed · Robert Dahlin · Malcolm Dick · \\ Camille Broadwater-Hollifield · Scott Mobley · Ira Lott · Eric Doran · Daniel Gillen • \\ Clifford Anderson-Bergman · David H. Cribbs $\cdot$ Charles Glabe $\cdot$ Elizabeth Head
}

Received: 4 December 2008/Revised: 11 March 2009/Accepted: 29 March 2009/Published online: 10 April 2009

(C) The Author(s) 2009. This article is published with open access at Springerlink.com

\begin{abstract}
Beta-amyloid (A $\beta)$ is thought to be a key contributor to the pathogenesis of Alzheimer disease (AD) in the general population and in adults with Down syndrome (DS). Different assembly states of $A \beta$ have been identified that may be neurotoxic. A $\beta$ oligomers can assemble into soluble prefibrillar oligomers, soluble fibrillar oligomers and insoluble fibrils. Using a novel antibody, OC, recognizing fibrils and soluble fibrillar oligomers, we characterized fibrillar A $\beta$ deposits in $\mathrm{AD}$ and $\mathrm{DS}$ cases. We further compared human
\end{abstract}

F. Sarsoza - T. Saing - R. Dahlin · M. Dick ·

C. Broadwater-Hollifield · S. Mobley · I. Lott .

E. Doran - D. Gillen - C. Anderson-Bergman .

D. H. Cribbs - C. Glabe - E. Head

Institute for Brain Aging and Dementia,

University of California, Irvine, CA 92697, USA

R. Kayed · C. Glabe

Department of Molecular Biology and Biochemistry,

University of California, Irvine, CA 92697, USA

I. Lott · D. H. Cribbs · E. Head

Department of Neurology, University of California,

Irvine, CA 92697, USA

I. Lott $\cdot$ E. Doran

Department of Pediatrics, University of California,

Irvine, CA 92697, USA

D. Gillen · C. Anderson-Bergman

Department of Statistics, University of California,

Irvine, CA 92697, USA

Present Address:

E. Head $(\square)$

Department of Molecular and Biomedical Pharmacology,

Sanders-Brown Center on Aging, University of Kentucky,

203 Sanders-Brown Building, 800 South Limestone Street,

Lexington, KY 40536, USA

e-mail: elizabeth.head@uky.edu specimens to those obtained from the $\mathrm{Tg} 2576$ mouse model of AD. Our results show that accumulation of fibrillar immunoreactivity is significantly increased in $\mathrm{AD}$ relative to nondemented aged subjects and those with select cognitive impairments $(p<0.0001)$. Further, there was a significant correlation between the extent of frontal cortex fibrillar deposit accumulation and dementia severity (MMSE $r=$ -0.72 ). In DS, we observe an early age of onset and agedependent accumulation of fibrillar OC immunoreactivity with little pathology in similarly aged non-DS individuals. $\operatorname{Tg} 2576$ mice show fibrillar accumulation that can be detected as young as 6 months. Interestingly, fibril-specific immunoreactivity was observed in diffuse, thioflavine $S$-negative $A \beta$ deposits in addition to more mature neuritic plaques. These results suggest that fibrillar deposits are associated with disease in both $\mathrm{AD}$ and in adults with $\mathrm{DS}$ and their distribution within early $A \beta$ pathology associated with diffuse plaques and correlation with MMSE suggest that these deposits may not be as benign as previously thought.

Keywords Diffuse plaques - Frontal cortex · Transgenic mouse $\cdot$ Trisomy 21

\section{Introduction}

Alzheimer disease (AD) is associated with the progressive development of cognitive dysfunction and neuropathological accumulation of neurofibrillary tangles and senile plaques (SP) [37, 53, 55, 67]. A major constituent of SP is $\beta$-amyloid (A $\beta)$, which is a $39-42$ amino acid peptide cleaved from a longer amyloid precursor protein (APP) $[25,33]$. A $\beta$ can adopt a misfolded structure including prefibrillar oligomeric and fibrillar assembly states $[9,24$, $28,42,70]$. Some assembly states of $A \beta$ may be more toxic 
than others [18, 42, 44, 71]. For example, $A \beta$ oligomers are toxic to neurons both in vitro $[18,42]$ and in vivo $[44,71]$. Thus, measuring the extent of different and specific assembly states of $A \beta$ may identify species that are more strongly linked to cognition in $\mathrm{AD}$ and can serve as a biomarker and possible therapeutic target [36].

Individuals with Down syndrome (DS) also develop AD pathology but in a progressive age-dependent manner [30, $49,50,77]$ and as such, are at high risk for the development of dementia [41, 46]. Clinical signs of dementia are more commonly observed when individuals are over 50 years of age $[8,41,63,69]$. By 40 years of age, however, all individuals with DS have neuropathological changes including senile plaques and neurofibrillary tangles consistent with $\mathrm{AD}[50,76,77]$. By studying individuals with varying ages at death, the progressive accumulation of $A \beta$ fibrils can be established as occurring early or late in $\mathrm{AD}$ pathogenesis.

We hypothesized that one conformation of $A \beta$ that may be linked to cognition in human brain is the accumulation of soluble and insoluble fibrils. We previously described a novel antibody, OC, that selectively recognized fibrils and fibrillar oligomers [35] that are distinct from prefibrillar oligomer assembly states. This new reagent was used to characterize and quantify the extent of fibrillar deposit accumulation in human brain by immunohistochemistry as a function of age (in DS) and dementia status (in AD). We further confirmed the age and disease-specific changes in A $\beta$ fibrils by examining $\mathrm{Tg} 2576$ (overexpressing human APP with the Swedish mutation [31]) mice with a wide range of ages and quantifying fibril accumulation.

\section{Methods}

Human autopsy cases

The first group of seven autopsy cases was used to characterize OC-associated pathology (neurofibrillary tangles, dystrophic neurites and glial activation). This study included two control cases (95 and 69 years) and five AD cases (65-89 years). A second group of 14 autopsy cases with MMSE scores ranging between 0 and 30 was used for OC load analyses and to measure associations between cognition and neuropathology (Table 1). Finally, tissues from a group of individuals with DS and similarly aged controls were compared (Table 1). Braak and Braak neurofibrillary tangle and senile plaque staging was provided as part of the standard neuropathology process [5-7]. A final neuropathology diagnosis was made according to NIA/Reagan criteria [67].

Brain tissue samples were obtained from the University of California Alzheimer Disease Research Center (UCIADRC) and from the NICHD Brain and Tissue Bank for Developmental Disorders (under contracts N01-4-3368 and N01-HD-4-3383). The hippocampus and midfrontal gyrus was dissected from $4 \%$ paraformaldehyde-fixed coronal slices and sectioned at $50 \mu \mathrm{m}$ using a vibratome. Freefloating sections were stored in PBS with $0.02 \%$ sodium azide prior to use in immunohistochemical or histology experiments.

\section{Transgenic mouse tissue}

Fixed free-floating 4\% paraformaldehyde-fixed sections that included the hippocampus from $\operatorname{Tg} 2576$ animals at 3, $6,9,12,18$ and 24 months ( $n=5$ /group) were compared with aged wild type animals that were either 18 months $(n=5)$ or 24 months $(n=5)$ of age. Brain tissues were obtained from the UCI-ADRC.

\section{Immunohistochemistry}

For single-labeling experiments, all sections were washed with $0.1 \mathrm{M}$ Tris-buffered saline (TBS), $\mathrm{pH} 7.5$, and then pretreated with $3 \%$ hydrogen peroxide in $10 \%$ methanol to block endogenous peroxidase activity. Sections were subsequently washed in TBS with $0.1 \%$ Triton X-100

Table 1 Case demographics

\begin{tabular}{|c|c|c|c|c|c|c|c|}
\hline Group & $N$ & Age (years) & Sex & PMI (h) & MMSE & Interval (Mos) & Braak stage \\
\hline \multicolumn{8}{|l|}{ Study 1} \\
\hline Nondemented & 4 & $80.0(7.12)$ & 4F/0 M & $3.6(1.26)$ & $29.5(0.58)$ & $6.9(4.2)$ & 3 (II), 1 (III) \\
\hline MCI/CIND & 4 & $83.5(2.08)$ & $0 \mathrm{~F} / 4 \mathrm{M}$ & $4.45(2.30)$ & $26.5(3.11)$ & $10.6(5.8)$ & 3 (II), 1 (III) \\
\hline $\mathrm{AD}$ & 6 & $79.8(5.23)$ & $4 \mathrm{~F} / 2 \mathrm{M}$ & $7.05(4.05)$ & $13.2(9.87)$ & $6.2(4.8)$ & $3(\mathrm{~V}), 3(\mathrm{VI})$ \\
\hline \multicolumn{8}{|l|}{ Study 2} \\
\hline Non-DS young & 6 & $22.3(12.0)$ & $3 \mathrm{~F} / 3 \mathrm{M}$ & $11.8(5.6)$ & N/A & N/A & N/A \\
\hline Non-DS old & 9 & $56.6(12.2)$ & $3 \mathrm{~F} / 6 \mathrm{M}$ & $7.4(4.6)$ & N/A & N/A & N/A \\
\hline DS-young & 5 & $19.0(16.6)$ & $1 \mathrm{~F} / 4 \mathrm{M}$ & $16.8(9.7)$ & N/A & N/A & N/A \\
\hline DS-old & 13 & $52.2(8.20)$ & 7F/6 M & $7.3(6.0)$ & N/A & N/A & N/A \\
\hline
\end{tabular}


(TBS-A) and then blocked for 30 min in TBS-A with $3 \%$ bovine serum albumin (TBS-B). Sections were incubated overnight at room temperature in previously established optimal primary antibody dilutions as indicated in Table 2. Following two washes with TBS-A and a wash in TBS-B, sections were incubated in either goat antimouse or goat anti-rabbit biotinylated anti-IgG and then in avidin biotin complex (ABC) (Vector Laboratories, Burlingame, CA, USA). Antibodies were visualized using horseradish peroxidase/3,3'-diaminobenzidine (ABC Elite kit, Vector Laboratories, Burlingame, CA, USA). For quantification experiments, the frontal cortex from all cases used for quantification was immunostained in single experiments to reduce variability in the image analysis procedures and all immunohistochemical procedures were identical for the OC antibody. To determine the specificity of the OC antibody, IgG purified from serum at a concentration of $1: 10,000$ was preincubated in $10 \times$ and $100 \times$ concentration of fibrillar A $\beta$ peptide for $2 \mathrm{~h}$ at RT. Subsequently, a section from the midfrontal cortex was incubated in the OC antibody/peptide solution and processed for immunohistochemistry.

\section{Immunofluorescence and confocal microscopy}

A series of double label immunofluorescence experiments were conducted to determine the colocalization characteristics of $\mathrm{OC}$ with other markers of pathology. Primary antibody dilutions are indicated in Table 2. Sections were incubated in OC overnight and then detected using antirabbit IgG Alexa Fluor 568 (Molecular Probes, Eugene, OR 1:200). The appropriate second antibody was used to serve as a marker for tau pathology (PHF-1), A $\beta$ (6E10), oligomers (A11), dystrophic neurites (ubiquitin), activated microglial cells (LN-3) and astrocytes (GFAP). In a subset of DS cases, additional double label immunofluorescence was completed using $A \beta 1-40$ and $A \beta 1-42$ antibodies after OC labeling. When possible, antibodies were selected that were raised in different hosts. When not possible, for double labeling experiments where both antibodies were raised in the same species an intervening formaldehyde treatment was used between the first and second immunolabel [72]. Alexa Fluoro 488 (Molecular Probes, Eugene, OR 1:200) was used to visualize the second label (PHF-1, ubiquitin, 6E10, LN-3, GFAP). Sections were allowed to dry on slides prior to rehydration and coverslipping with VectaShield (Vector Laboratories, Burlingame, CA, USA). Confocal images were collected on a BioRad Radiance 2000 Confocal Imaging System with an Olympus IX70 inverted microscope using a 40, 60 or $100 \times$ objective for image analysis. Each antibody label was excited and scanned separately using barrier filters at 510 and $480 \mathrm{~nm}$. Channel 1 was used to acquire immunofluorescence with Alexa Fluor 488 and channel 2 was used to collect fluorescent labeling with Alexa Fluor 568. A z-series scan at either 0.5 or $1 \mu \mathrm{m}$ intervals was captured to determine the spatial colocalization characteristics of OC with other markers of pathology. A subset of sections was first immunostained for OC and visualization with Alexa Fluor 568 and then counterstained with thioflavin S.

\section{Quantification}

\section{OC loads}

Immunostaining by the $\mathrm{OC}$ antibody was captured from a single section for each $\mathrm{AD}, \mathrm{DS}$ and control case using a $20 \times$ objective, a Sony high-resolution CCD video camera (XC-77) and the built-in video capture capabilities of a Macintosh 8100/80AV. A random superficial cortical region containing $\mathrm{OC}$ immunostaining in samples that were positive was selected and captured. For control cases, OC immunostaining was scattered and thus the first sample was selected to include positive immunoreactivity if present, or a random area if absent. This sampling approach is slightly modified from that used by Cummings et al. [13], in that

Table 2 Antibodies used in the study

\begin{tabular}{|c|c|c|c|c|}
\hline Antibody & Used to detect & Type & Dilution & Source \\
\hline PHF-1 & Neurofibrillary tangles and dystrophic neurites & Monoclonal & $1: 1,000$ & $\begin{array}{l}\text { Dr. Peter Davies (Albert Einstein College } \\
\text { of Medicine, Bronx, NY, USA) }\end{array}$ \\
\hline $6 \mathrm{E} 10$ & Senile plaques (Abeta 1-16) & Monoclonal & $1: 5,000$ & $\begin{array}{l}\text { Signet Laboratories, Inc., Dedham, MA, } \\
\text { USA }\end{array}$ \\
\hline A11 & Oligomers & Polyclonal & $1: 100$ & Glabe-UCI \\
\hline Anti-ubiquitin & Dystrophic neurites & Polyclonal & $1: 1,000$ & Novus Biologicals, Littleton, CO, USA \\
\hline Anti-GFAP & Astrocytes & Polyclonal & $1: 2,500$ & $\begin{array}{l}\text { Chemicon International, Temecula, CA, } \\
\text { USA }\end{array}$ \\
\hline LN-3 & Activated microglial cells & Monoclonal & $1: 100$ & ICN Biomedicals, Irvine, CA, USA \\
\hline Anti-A $\beta 1-40$ & $\mathrm{~A} \beta 1-40$ & Polyclonal & $1: 1,000$ & BioSource International \\
\hline Anti-A $\beta 1-42$ & $\mathrm{~A} \beta 1-42$ & Polyclonal & $1: 2,000$ & BioSource International \\
\hline
\end{tabular}


we did not begin with a sample that appeared to have the highest amount of $\mathrm{OC}$ immunoreactivity in $\mathrm{AD}$ cases. From that initial sample area, four adjacent superficial fields were captured that were non-overlapping. Subsequently, the tissue was shifted to capture five deep cortical fields that were non-overlapping but adjacent. Thus, a total of 10 fields (including 5 superficial and 5 fields containing deep layers of cortex) were quantified from the midfrontal gyrus for each human case. For the transgenic mouse study, OC loads were obtained from the frontoparietal cortex, the entorhinal cortex and from area CA1 in the hippocampus of individual animals. To do this, two samples from each cortical region was captured by starting above the cingulate cortex and moving laterally for the frontoparietal measures (fields captured included a superficial and deep layer sample), and from the most ventrolateral aspect of the entorhinal cortex and moving dorsally. Fewer samples were taken in mice as the cortical areas were smaller but to maintain consistency with the human study, the same magnification and capturing process was used. For area CA1 in the hippocampus, a single field was captured that contained CA1 neurons as a row of cells through the center of the field. All samples from a given region were captured sequentially during one session. Subsequently, public domain image analysis software (NIH Image 1.55) and a gray-scale threshold of 110 were used to separate positive staining from background and to calculate the percentage of area occupied by OC-positive labeling. The threshold cutoff point was selected to be conservative and resulted in a slight underestimation of the stained areas but minimized the impact of non-specific background reactivity. With this technique, individually captured fields measured $525 \times 410 \mu \mathrm{m}$, which would allow us to quantify diffuse plaques and neuritic plaques, however, deposits that occupied less than $1 \%$ of any given area would not be included due to the thresholding.

\section{OC colocalization with neuritic and diffuse plaques}

To obtain measures of co-localization between OC-positive immunolabeling and neuritic plaques or diffuse plaques, additional images were analyzed from confocal microscopy experiments. Confocal images captured from three Down syndrome cases and with three controls were used to obtain either neuritic plaque (thioflavin S-positive with OC) or diffuse plaque colocalization (using OC and 6E10 labeled sections in cases that were thioflavin S-negative). One image was captured (using a $20 \times$ objective such that 1 pixel $=0.18 \mu \mathrm{m}$ ) for each case for each double labeling experiment. Image J (Rasband, W. S., ImageJ, U. S. National Institutes of Health, Bethesda, MA, USA, http://rsb.info.nih.gov/ij/, 1997-2008) and the JACoP plug in [4] was used to obtain Manders' overlap coefficients, which provides a proportion of the "green signal" coincident with the "red signal". Images were thresholded prior to quantification by first determining a cut off for the marker (OC or thioflavin or 6E10) that occupied the most area in the image with the second marker automatically set to the same threshold.

\section{Statistical analysis}

Linear regression analyses using the Huber-White robust standard error estimator [74] were used to evaluate group differences while co-varying for post mortem interval and age at death.

\section{Results}

OC antibody characteristics

To determine if OC labeling was sensitive to formic acid pretreatment, a procedure used to improve immunostaining for fibrils [39], serial sections from an $\mathrm{AD}$ case were pretreated with $0,10,50,70$ and $90 \%$ formic acid for 4 min prior to incubation in OC antibody. After visualization with anti-rabbit conjugated to Alex Fluor 568, sections were washed and then incubated in 6E10, which shows an increase in immunolabeling with increasing formic acid. Figure 1 shows confocal images from a similar region in each serial section illustrating that increasing formic acid concentration leads to increasingly extensive $6 \mathrm{E} 10$ labeling but there is no change in $\mathrm{OC}$ labeling. We next examined whether OC immunoreactivity co-localizes with thioflavine-S, a marker for betapleated sheet fibrils but that there would also be distinct deposits. Figure 2 shows that some OC-positive deposits are also positive for thioflavin S suggesting an association with mature plaques $(63.4 \%$ of thioflavin $\mathrm{S}$ was positive for OC). However, additional thioflavin-negative deposits were detected by the OC antibody, particularly at the periphery of mature plaques. It is possible that the OC antibody can detect other types of amyloid such as, for example, fibrillar oligomers that are thioflavine S-negative or alpha synuclein [35]. Further, OC-positive deposits had a distinct morphology from thioflavine S-positive fibrils (Fig. 2a-c). Using tissue from a nondemented elderly subject (Fig. 2d-f) and a younger individual with DS (Fig. $2 \mathrm{~g}-\mathrm{i}$ ), both having primarily diffuse plaques (thioflavine S-negative), we observed that diffuse plaques are also OC-positive $(9.3 \%$ of OC-positive plaques were thioflavin S-positive).

Additional experiments in DS and control cases were used to measure the overlap in immunostaining between $\mathrm{OC}$ and $\mathrm{A} \beta 40$ or $\mathrm{A} \beta 42$. When both $\mathrm{OC}$ and $\mathrm{A} \beta 40$ were 
Fig. 1 Formic acid pretreatment has little effect on OC labeling intensity. Increasing concentrations of formic acid pretreatment (a none, b $10 \%$, c 50\%, d 70\%, e $90 \%$ ) were used in an AD case (frontal cortex) to illustrate no change in OC (red fluorescence) immunolabeling but an increase in $6 \mathrm{E} 10$ (green fluorescence) labeling. Note that with increasing formic acid and corresponding increase in $6 \mathrm{E} 10$ labeling, the extent of co-localization of the two markers also increases (orange fluorescence). In comparison, a control case shows neither significant $\mathrm{OC}$ nor 6E10 immunolabeling (f). However, a subset of OC-positive deposits ( $\mathbf{g}$ and $\mathbf{i}$ ) was negative for 6E10 (h and i)
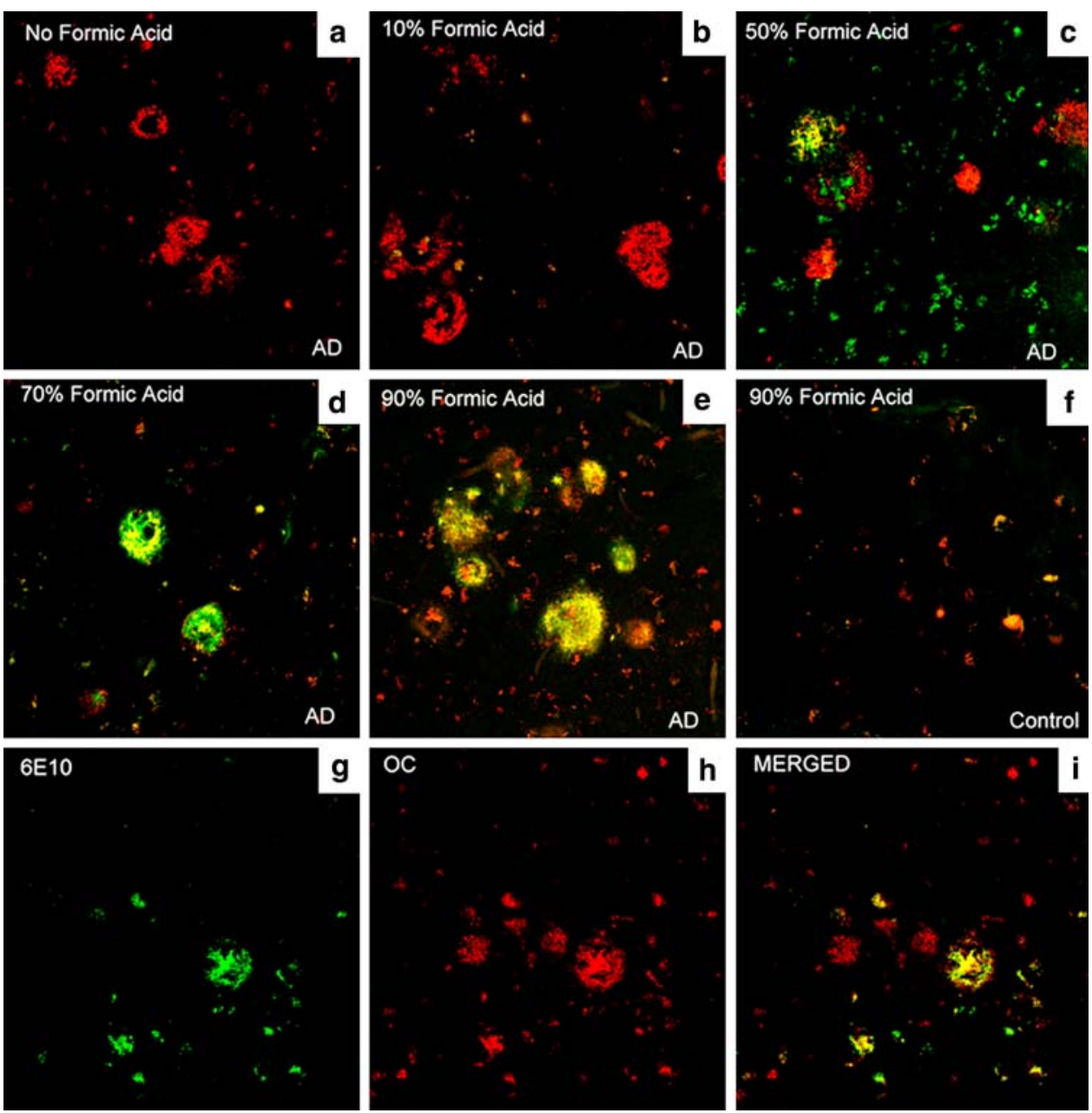

present, we observed a range of colocalization from 17.6 to $62.5 \%$ of OC-positive deposits containing $A \beta 40$. However, we observed individual plaques that were $A \beta 40$-positive and OC-negative. Similarly for OC and A $\beta 42$, when both were present, OC occupied $38.5 \%$ of A $\beta 42$-positive plaques. However, we observed A $\beta 42$-positive plaques that were also negative for OC. Thus, in this small set of samples, we observed both $\mathrm{A} \beta 40$ and $\mathrm{A} \beta 42$-positive plaques that were negative for OC but when both are present, there was a higher association with $\mathrm{OC}$ to $\mathrm{A} \beta 40$. OC-positive deposits could also be distinguished from A11-positive oligomers in mature plaques observed in DS (Fig. 2j-m).

OC-positive deposits were characterized further to determine if they were associated with dystrophic neurites and glial cell responses (Fig. 3). OC-positive deposits contain PHF-1 (Fig. 3a) and ubiquitin (Fig. 3c) positive dystrophic neurites but a subset were negative (Fig. 3b). Microglial activation (Fig. 3d, e) was associated with a subset of OC-positive fibrils and a subset of microglia appear to have phagocytosed OC-positive material within vacuoles (Fig. 3f). OC-positive deposits were also surrounded by hypertrophic astrocytes (Fig. 3g, h).

OC immunostaining in $\mathrm{AD}$ and controls

To test the hypothesis that the extent of OC-positive fibrils was higher in $\mathrm{AD}$ cases relative to controls, and intermediate within those cases with select cognitive impairments (cognitively impaired not demented-CIND or MCI), OC labeled frontal cortex sections were quantified. Robust linear regression was used to test for group differences, adjusting for PMI and age at death. After adjusting for PMI and age, there was a statistically significantly higher OC percentage load in $\mathrm{AD}$ patients compared to controls $(p$ value $=0.002,95 \%$ CI for difference $=12.09,37.56)$ (Fig. 4a). Significant differences in OC load were observed as a function of Braak and Braak tangle staging primarily due to higher levels in Braak stage V/VI $(p=0.002)$ (data not shown). Figure $4 \mathrm{~b}$ shows the results of a linear regression that included the interval between last clinic visit and death, that as dementia severity increases (low 

distinct from thioflavine and also identifies diffuse plaque deposits. OC-positive deposits (a) had a distinct morphology that appears as shorter aggregates (red) as compared to thioflavine S-positive fibrils (green) (b). Further, when OC and thioflavine-S was colocalized within plaques (orange), OC periphery $(\mathbf{c})$. Using tissue from a nondemented elderly subject (d-f) and a younger individual primarily diffuse plaques (thioflavine S-negative-green), we observed that diffuse plaques are also OC-positive (red). A z-scan shows that OC-positive deposits (green) could also be distinguished from A11-positive oligomers ( $r e d)$ in mature plaques observed in DS frontal cortex
Fig. 2 OC immunolabeling is S-positive fibrils within plaques labeling was more intense in the with DS ( $\mathbf{g}-\mathbf{i})$, both having
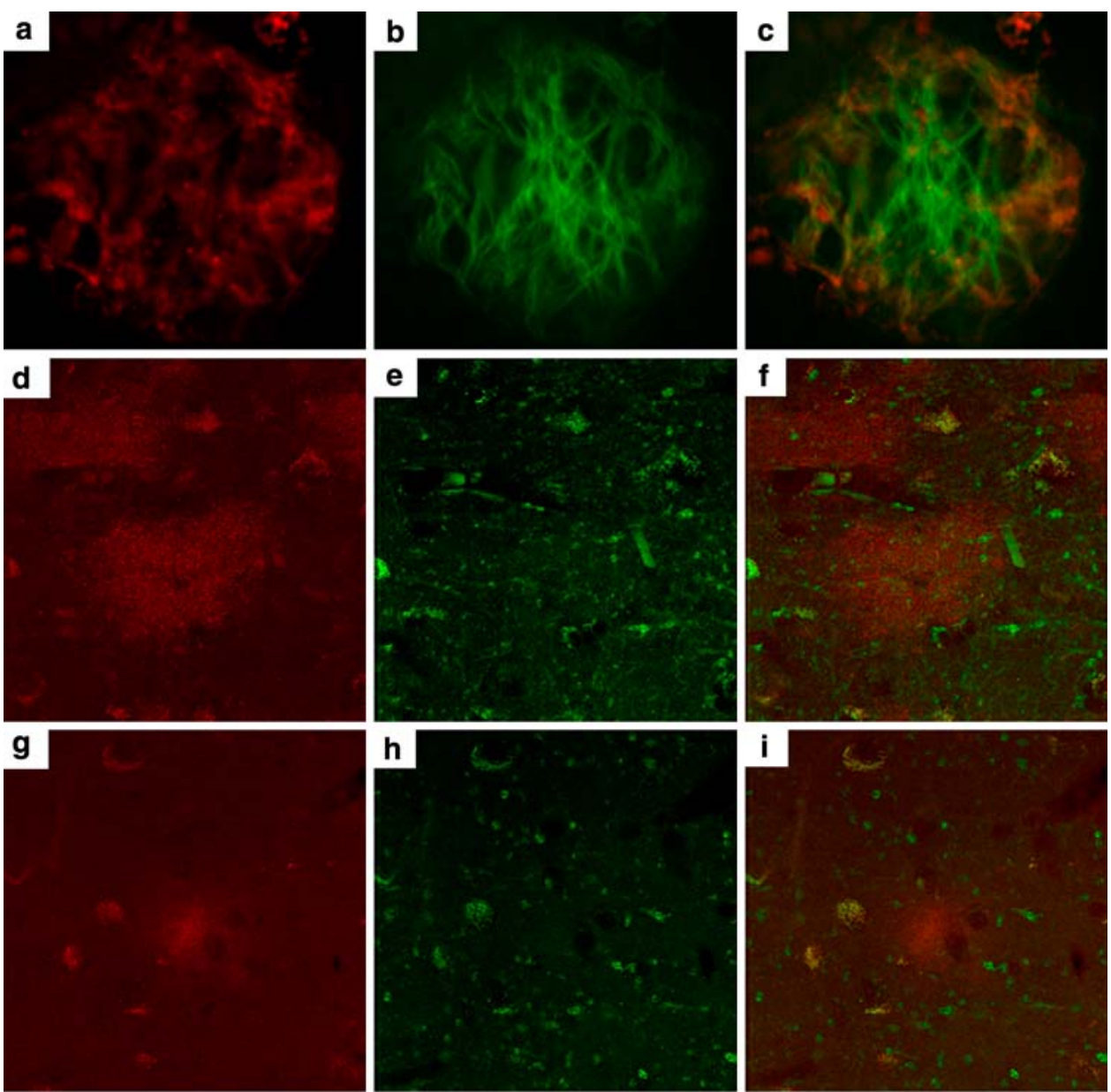

h
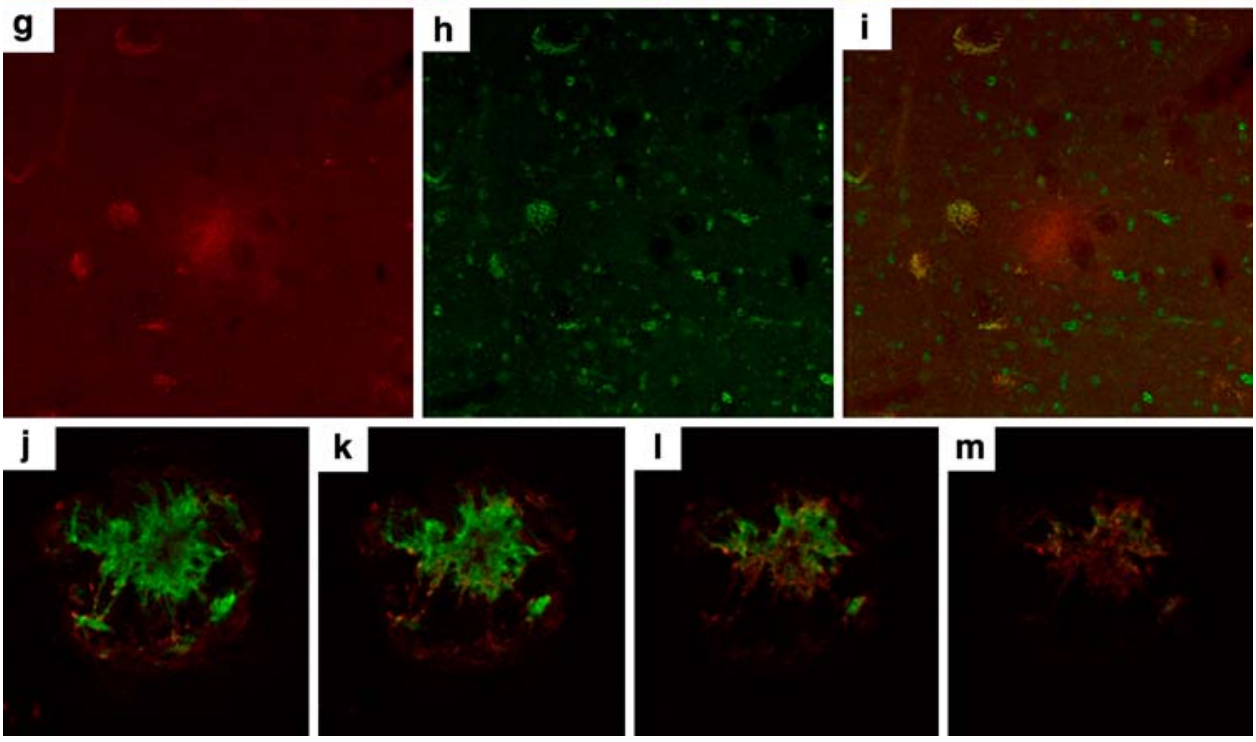

MMSE score) there was a corresponding increase in OC load $(p=0.0007)$.

\section{OC in Down syndrome}

We next asked the question whether OC immunoreactivity accumulates as a function of age in DS cases, where typically, virtually all cases over the age of 40 years have sufficient pathology for a diagnosis of AD [50]. We first tested the hypothesis that PMI was not a significant contributor to OC load. However, we observed a significant association of PMI with OC load ( $p=0.001)$ with longer PMI's associated with a loss of OC immunoreactivity and a $2.5 \%$ decrease in OC labeling with each 10-h block of PMI (Fig. 4c). We further found a significant interaction between age and genotype group (DS vs. non-DS) with aged DS individuals having higher overall levels of OC labeling ( $p=0.0004$ ) (Fig. 4d).

OC in $\operatorname{Tg} 2576$ mice

Age-associated increases in OC labeling in individuals with DS may be due to overexpression of the human APP gene. To confirm and extend this hypothesis, we used tissue from $\operatorname{Tg} 2576$ mice, which overexpress mutant human APP [31]. In a study of the brains of $30 \mathrm{Tg} 2576$ animals, we find a significant main effect of age on OC loads in the frontoparietal cortex $(F(5,29)=5.90, p=0.001)$, in the entorhinal cortex $(F(5,29)=9.91, p<0.0005)$ and in area CA1 of the hippocampus $(F(5,29)=9.94, p<0.0005)$. Figure 5 shows that as with DS cases, there was a sudden rise in the extent of OC labeling after the age of 12 months 
Fig. 3 Characteristics of OC-positive deposits. A subset of OC deposits (red) contained dystrophic neurites labeled by PHF (green arrows) that could be distinguished from tangle bearing neurons (arrowheads) (a). Not all OC (red) deposits contained PHF positive dystrophic neurites (green) (b). Dystrophic neurites labeled with ubiquitin (green) were also found in association with a subset of OC deposits (red) (c). A subset of OC (red) deposits was associated with activated microglial (LN-3 green) (d) Area in $\mathbf{d}$ indicated by asterisk at higher magnification illustrating two activated microglial cells (green) surrounding an OC-positive deposit (red) (e). A subset of activated microglial cells (green) appear to have engulfed OC-positive material (arrows red/orange) whereas other microglial cells appear OC-negative (arrowhead) (f). OC-positive deposits (red) are surrounded by astrocytes (green) (g). A higher magnification of the region in $\mathbf{g}$ indicated by the asterisk shows that some astrocytes in proximity to OC appear hypertrophied (h)

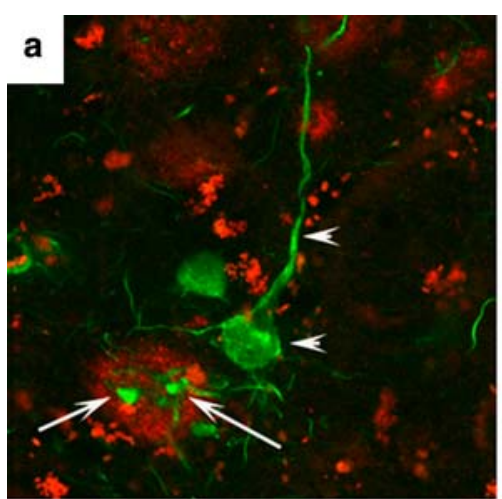

b
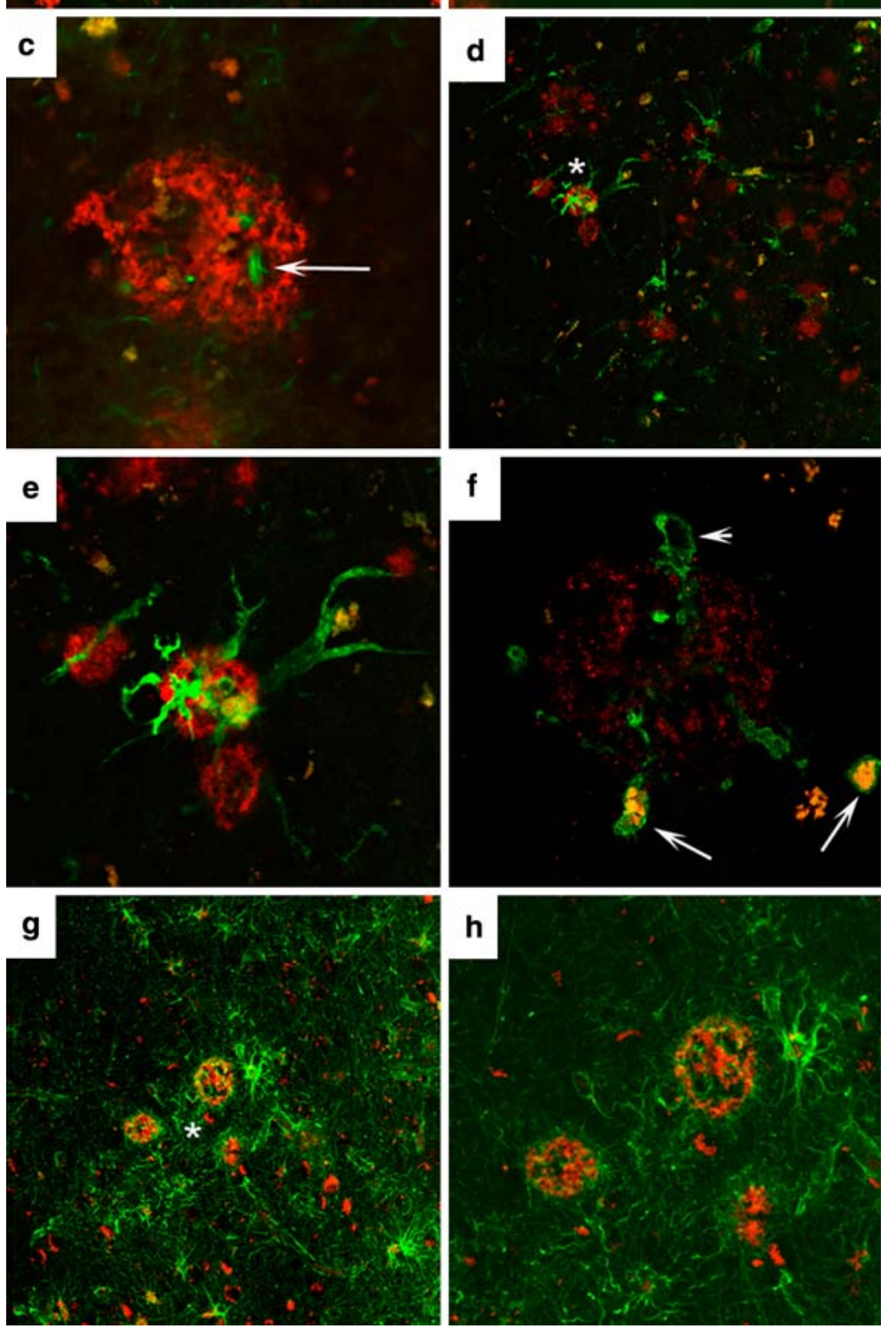

in Tg2576 animals. Initial deposits were observed at 6 months in one animal and in 4/5 animals at 9 months of age. When 18- and 24-month old Tg2576 mice were directly compared to wild type animals of the same ages, the latter group had undetectable amounts of OC-positive deposits (data not shown).

\section{Discussion}

Using a newly developed conformation-dependent, fibrilspecific, polyclonal antibody [35] that recognizes a generic epitope associated with fibrils and soluble fibrillar oligomers we have characterized $\mathrm{AD}$ and age-associated 

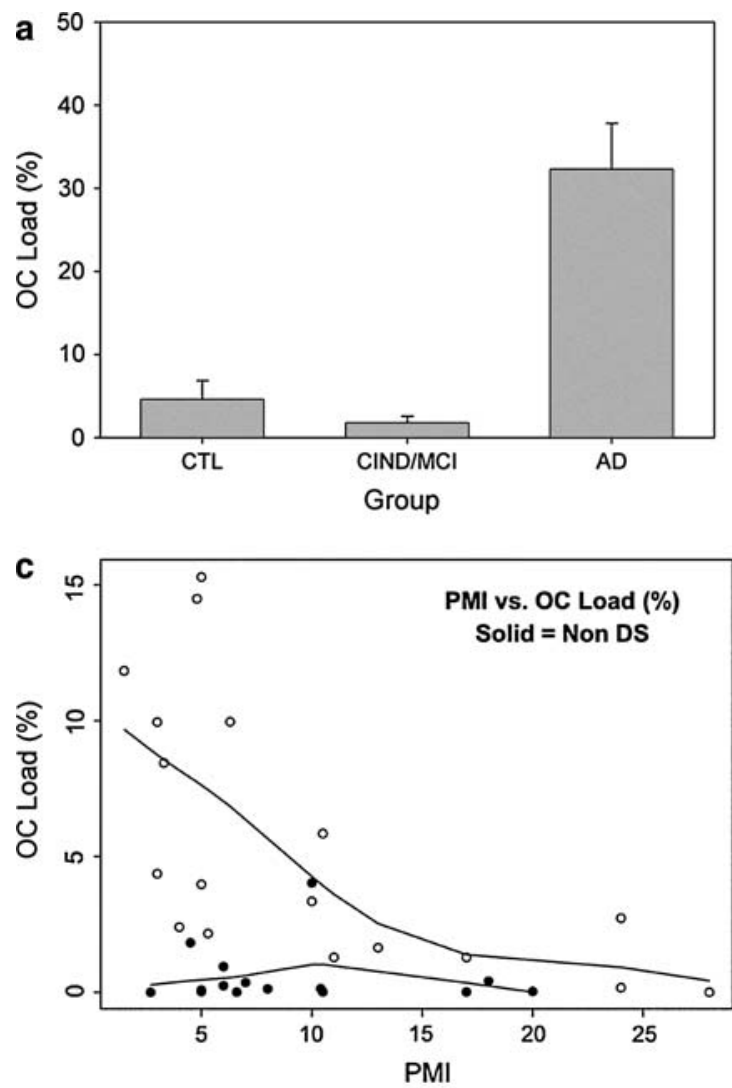

Fig. 4 The extent of $\mathrm{OC}$ labeling in $\mathrm{AD}$ and $\mathrm{DS}$ brain. More extensive $\mathrm{OC}$ immunoreactivity was observed in the $\mathrm{AD}$ cases relative to both the control and MCI/CIND cases (a). Higher MMSE scores were associated with less extensive OC immunolabeling $(r=-0.72, p<0.001)$ (b). In DS cases used in experiment 2, OC labeling appears to be significantly reduced when the PMI is over $10 \mathrm{~h}(\mathbf{c})$. A significant increase in OC was observed in adults with DS

changes in $A \beta$ fibril accumulation. Several technical aspects to the use of the OC antibody were identified in the current study. First, formic acid pretreatment, typically used to enhance $A \beta$ immunostaining [39] does not significantly improve OC labeling. This suggests that the epitope/conformation recognized by the OC antibody is not obscured when fibrils form and have not adopted a full beta-pleated sheet assembly state. Second, based on our studies in DS brain, post mortem interval may be a key factor to consider when using this antibody. Longer postmortem intervals $(>10 \mathrm{~h})$ may be associated with a degradation of the signal, possibly related to protease activity. Whether this represents a loss of tissue morphology, a spontaneous disassembly of fibrils or oligomeric protofibrils or the opposite, a conversion into beta-pleated sheet fibrils post mortem, is difficult to determine. Further, a PMI effect on OC immunolabeling may potentially distinguish sporadic AD deposits from DS with AD deposits and there is some evidence that the properties of $A \beta$ in these two groups may behave differently [1].
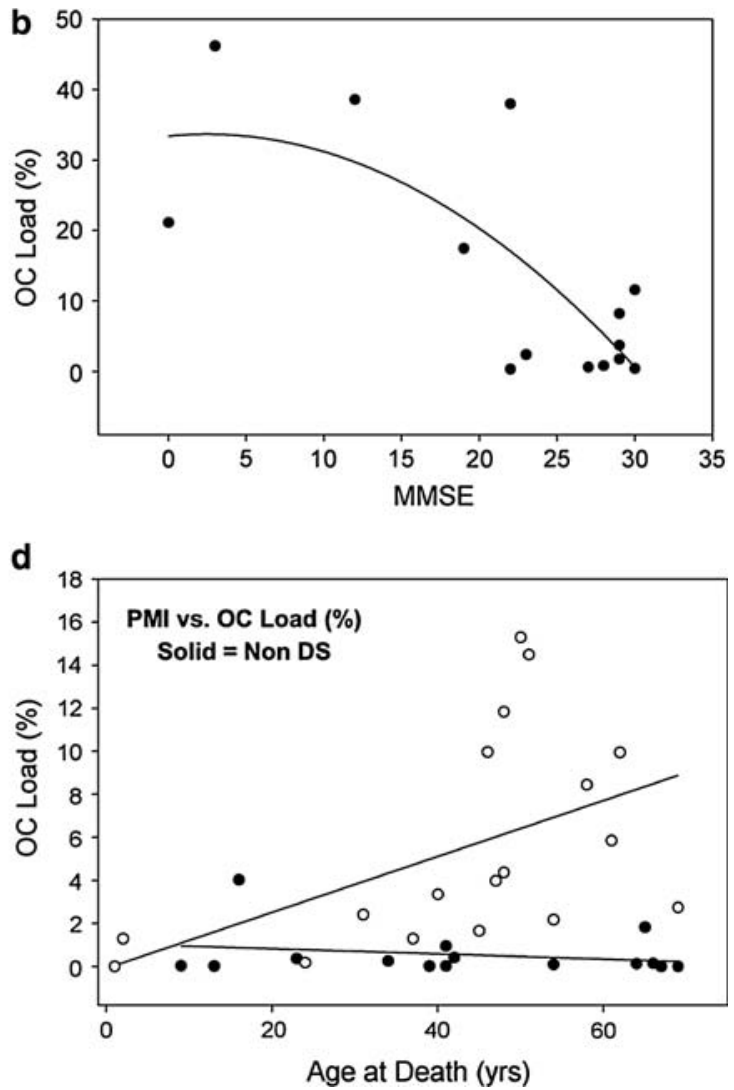

over the age of 40 years (open circles $\mathbf{d}$ ) but not in similarly aged non-DS controls (closed circles). When OC loads are plotted as a function of individual age, there is an exponential rise in $A \beta$ fibril accumulation after the age of 40 years in DS (open circles) but not in non-DS controls (closed circles) (d). Bars represent means and error bars, standard errors of the mean. In $\mathbf{b}-\mathbf{d}$, the lines represent a best fit function

OC-positive fibrillar deposits accumulate in human brain as overlapping deposits with thioflavine-S plaques but are also found in deposits that are diffuse, i.e. thioflavine S-negative. By examining the brains of individuals with and without dementia, we show increased fibrillar accumulation in $\mathrm{AD}$ but when compared to controls. However, CIND/MCI cases showed similar OC immunolabeling as controls. Further, the extent of fibril accumulation in $\mathrm{AD}, \mathrm{CIND} / \mathrm{MCI}$ and control brain correlates with the severity of cognitive decline measured by MMSE scores. Similarly, in individuals with DS, we observe fibril accumulation that is both age- and AD neuropathology-associated but with a rapid rise in levels after the age of 40 years. Finally, in one of the most commonly used animal models of $\mathrm{A} \beta$ pathogenesis, we find a rapid age-dependent accumulation of fibrils that is first detectable at 6 months of age but dramatically increases after 12 months of age after overexpression of mutant human APP in the Tg2576 model system. Thus, OC-positive deposits may be visible histologically at an earlier age than 
Fig. 5 OC fibril labeling in Tg2576 animals. a Tg2576 animals show increasing OC accumulation with age while no OC was observed in comparably aged wild type animals.

OC loads were obtained from the $\mathbf{b}$ frontoparietal cortex, c entorhinal cortex and $\mathbf{d}$ from area CA1 in the hippocampus of individual animals. Mean loads are plotted as a function of age for each brain region and show a dramatic increase after 12 months of age in cortical regions but with a slower more progressive rise in the hippocampus. Error bars represent standard errors of the mean ( $n=5$ animals/age group)
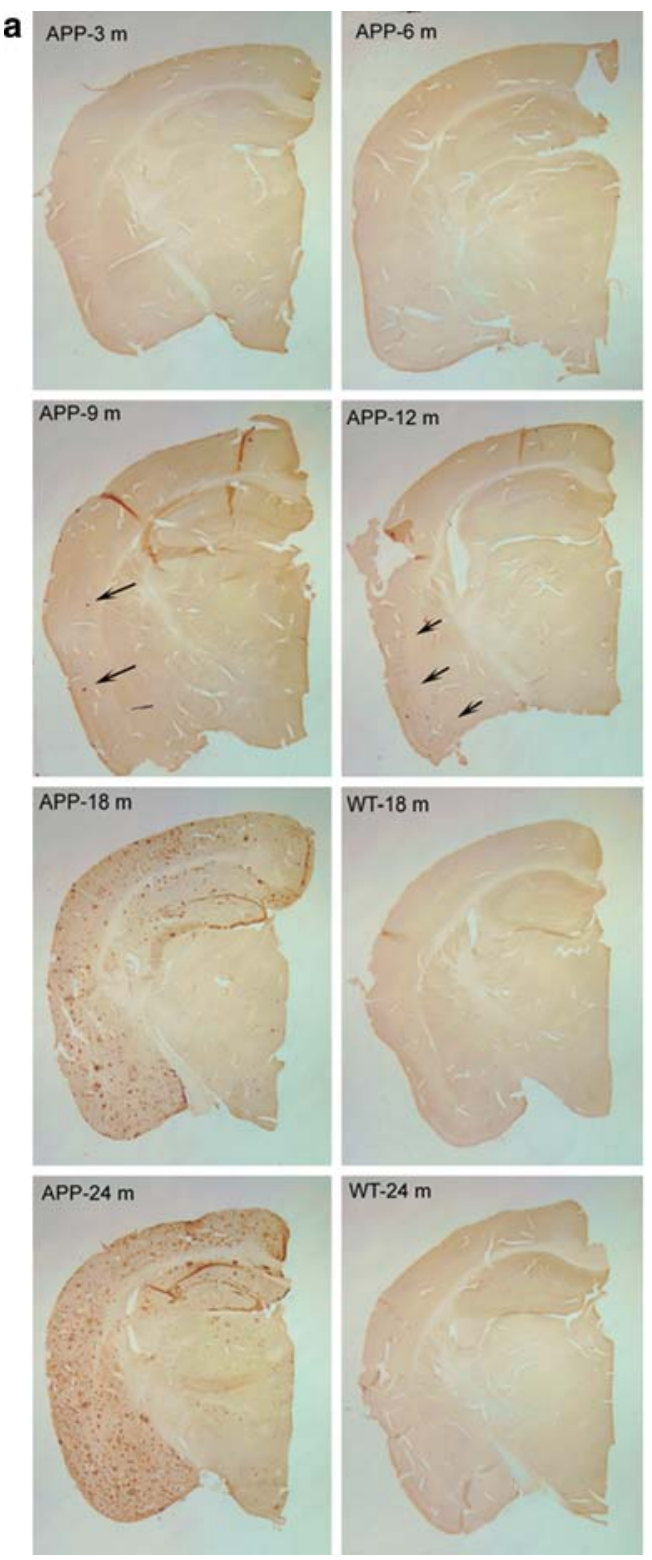
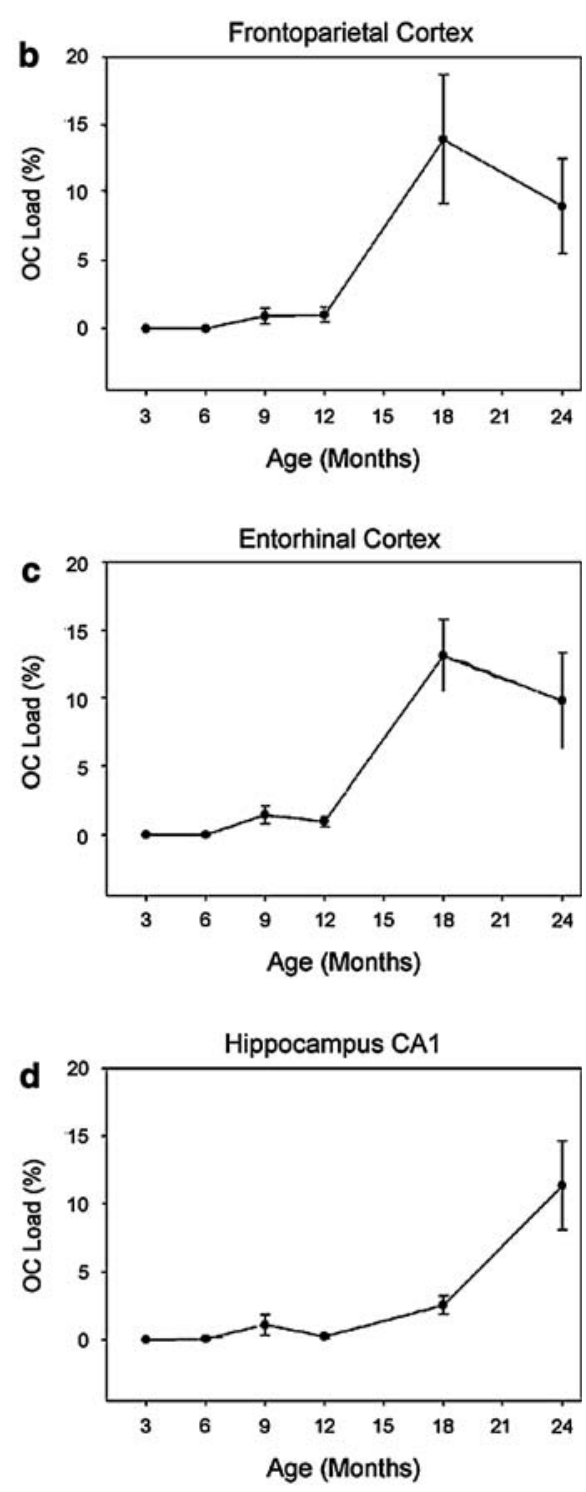

A $\beta$-positive deposits reported previously [34] and may represent an early neuropathological feature more consistent with the onset of behavioral dysfunction [31].

OC-positive deposits that are thioflavine S-negative may reflect fibrillar oligomers. This is consistent with reports that protofibrillar forms of $\mathrm{A} \beta$ have low thioflavine- $\mathrm{T}$ response [75]. The morphology of the OC-positive, thioflavine S-negative deposits are distinct and appear to be shorter and wider than thioflavine S-positive fibrils. In addition, we frequently find OC-positive deposits at the periphery of thioflavine S-positive plaques providing further evidence that soluble fibrillar oligomers may represent a reservoir for fibril formation [35]. OC, interestingly, was also able to detect diffuse plaques characterized as being thioflavine S-negative but also containing intact neurons.
This may suggest that the pathogenesis of diffuse plaques involves the accumulation of thioflavine S-negative fibrils and soluble fibrillar oligomers. Interestingly, a similar conclusion was made in an earlier study by Davies and Mann [16] based on electron microscopy in biopsy samples from $\mathrm{AD}$ cases showing diffuse plaques contained fibrillar material. Parallel studies in the canine model, that only develop diffuse $A \beta$ plaques also suggests that these early deposits are fibrillar in nature [68]. Indeed, diffuse plaques, though to be one of the earlier plaque subtypes accumulating $A \beta$ pathology [27], contain primarily the longer toxic $A \beta 1-42$ peptide $[15,26,32]$, are observed at the threshold of detectable dementia [56], can occur after traumatic brain injury leaving affected patients at higher risk for developing $\mathrm{AD}$ [17] and may reflect synaptic activity induced $\mathrm{A} \beta$ 
production and release into the interstitial space [10]. Further, individuals with early onset AD caused by a missense mutation in APP (T714I), develop primarily diffuse $\mathrm{A} \beta$ deposits and an aggressive form of dementia [40]. In combination, diffuse plaques may not be entirely benign as has been suggested previously [51] although they may be "clinically silent".

When OC is detected in more compact plaques, we observe dystrophic neurites, microglial and astrocyte involvement similar to previous reports of associated neurodegeneration in these more mature plaque subtypes [19]. Further, microglial cells may engulf OC-positive deposits for degradation as we observe OC-positive material within phagocytic vacuoles within HLA-DR expressing microglial cells. We have observed a similar phenomenon with oxidatively modified $A \beta$ [29] and others have reported $\mathrm{A} \beta$ within microglial cells in vitro and within $\mathrm{AD}$ brain previously $[21,22,60,61,65]$. A critical role for microglial cells in clearing $A \beta$ from the brain has been established in transgenic mice [3] and the results from this study also suggest efforts by microglial cells to clear soluble and insoluble fibrils.

\section{OC fibrils in $\mathrm{AD}$}

We next used the OC antibody in studies to quantify the extent of fibril formation in individuals with and without AD. OC-positive deposits were 7-fold higher in AD brain relative to controls. However, based on previous studies in the brains of individuals with MCI [57], we also predicted that subjects with MCI or with a cognitive impairment although not demented, may be either equivalent or intermediate with respect to extent of OC-positive deposits. However, we found that OC fibrils were similar in MCI/ CIND as compared to nondemented aged controls. There are two possible interpretations of these data. The first is that given our sample consisted primarily of CIND subjects; there is a less clear relationship between CIND and progression to dementia as in MCI [62]. Second, fibrils may be more closely associated with full-blown dementia rather than a possible pro-dromal selective clinical impairment. By immunohistochemistry, we may also be detecting primarily fibrils as opposed to soluble oligomeric fibrils, the latter may be optimally detected using biochemical methods [35]. Measures of soluble fibrillar oligomers from protein extracts of frozen tissue in these cases may be more sensitive and reveal higher levels of OC in MCI/CIND cases relative to controls because they have the potential of distinguishing insoluble fibrils and soluble fibrillar oligomers; both of which react with OC. Another important consideration is that the current study focused on plaque pathology in the frontal cortex and had we sampled regions in other vulnerable areas, particularly the entorhinal cortex (which was not available for all cases), we may have observed OC levels that are more consistent between MCI/CIND cases and $\mathrm{AD}$ cases.

In $\mathrm{AD}$ brain, there are various reports of a correlation between the extent of $A \beta$ deposition in plaques and the severity of cognitive decline. For example, several studies show a significant inverse correlation with MMSE scores, suggesting that lower scores associated with dementia are linked to more extensive plaque formation [2, 13, 20, 58]. In contrast, additional studies do not show this relationship and/or find that neurofibrillary tangles or synapse protein loss, other key pathological features of $\mathrm{AD}$, are also tightly linked to cognition $[12,14,23,52,58,66]$. Various interpretations of these results have been suggested but one hypothesis is that assembly state of $A \beta$ may be a critical factor in determining its toxicity and thus the link to impaired cognition. The current study suggests a significant correlation between OC-positive fibrillar deposits and MMSE scores with higher scores associated with intact cognition linked to lower levels of OC. Interestingly, we may be observing a threshold effect as OC loads increase significantly when MMSE scores drop below 20 but this should be confirmed in a larger cohort of cases.

\section{OC fibrils in Down syndrome}

In the most common form of DS, trisomy 21, chromosome 21 is present in triplicate and leads to lifelong overexpression of the APP gene (21q21.2) [64]. Despite this lifelong overexpression of APP in brain and in peripheral lymphocytes [59, 64], $A \beta$ accumulation in plaques does not typically begin until after the age of 30 years [50], although there have been reports of plaques in younger individuals [43, 45]. Interestingly, the incidence of dementia typically does not increase until adults with DS are over the age of 50 years [41], suggesting the possibility that either the brain can compensate for significant $A \beta$ accumulation or that $A \beta$ must adopt a specific conformation to become neurotoxic.

To test this hypothesis, we measured OC loads in individuals with DS with a range of ages. In the second experiment, we observed an age-associated increase in OC in DS that was not observed in similarly aged non-DS subjects without dementia. In DS, it is possible to differentiate initiation from acceleration phases of $\mathrm{AD}$ pathogenesis. Between the ages of 30-40 years, the first signs of $\mathrm{A} \beta$ plaques appear as diffuse deposits [47, 48]. Between 40 and 50 years, neurofibrillary tangles also form and neuritic plaques appear suggesting an acceleration phase. We may also consider from 50 years and older as when functional declines may occur [41]. If we classify adults with DS into these groups, OC-positive fibrils are found as early as the initiation phase suggesting a key role 
in $A \beta$ pathogenesis in DS. Despite life-long overexpression of APP, the brains of individuals with DS under the age of 30 years were negative for fibrils, however, a larger sample of individuals between 20 and 30 years would extend these findings. Thus, OC-positive deposits appear prior to the age at which dementia prevalence rises in DS and may play a role in $\mathrm{AD}$ pathogenesis in DS.

\section{OC fibrils in $\operatorname{Tg} 2576$}

Similar to individuals with DS, transgenic mouse models that overexpress mutant human APP develop A $\beta$ pathology in a progressive age-dependent manner [31, 34]. In a systematic study of the different types and assembly states of $\mathrm{A} \beta$ that accumulate in $\mathrm{Tg} 2576$ mice, Kawarabayashi and colleagues [34] showed that $A \beta$ in the form of plaques appear as early as 7-8 months whereas diffuse plaques appear between 12 and 15 months. However, $A \beta$ extracted with formic acid can be detected using biochemical approaches younger ages between 6 and 8 months. Further, A $\beta$ oligomers are detected in older animals $\sim 12$ months of age as variably being increased [34] or decreased [44]. However, behavioral impairments may appear prior to significant $\mathrm{A} \beta$ plaque pathology as early as 3 months [38], 6 months of age [73] or older [11,31,54]. The discrepancy between the onset of behavioral dysfunction in $\mathrm{Tg} 2576$ mice and the age at which $A \beta$ plaques first appear suggests a critical role for different assembly states of $A \beta$ on neuronal function. The earliest age at which we consistently observed OC-positive deposits in the $\mathrm{Tg} 2576$ mice in the current study was 9 months, with one animal at 6 months of age showing pathology, but this does not rule out soluble fibrillar oligomers, which may not be detected by immunohistochemistry, from being a contributor to neuronal dysfunction. Indeed, $A \beta * 56$ oligomers that appear as early as 7 months are A11-positive, indicating that they are prefibrillar oligomers that would not be expected to react with OC [44].

In summary, using a novel antibody that detects amyloid fibrils and soluble oligomeric protofibrils we show a differential distribution from beta-pleated sheet fibrils and association with $\mathrm{AD}$ in both the general population and in adults with DS. Further, OC-positive fibrils also accumulate in $\mathrm{Tg} 2576$ mice suggesting that several of the dynamics involved with production and accumulation of fibrils may be modeled in this animal. It would be interesting to selectively reduce OC-positive fibrils through a vaccination approach to determine their functional impact.

Acknowledgments Funding provided by the UCI-ADRC National Institutes on Health/National Institute on Aging Grant number P50 AG16573, National Institutes on Health/National Institute on Aging P01 AG000538. NICHD Brain and Tissue Bank for Developmental
Disorders is supported under contracts N01-4-3368 and N01-HD-43383.

Open Access This article is distributed under the terms of the Creative Commons Attribution Noncommercial License which permits any noncommercial use, distribution, and reproduction in any medium, provided the original author(s) and source are credited.

\section{References}

1. Armstrong RA (1999) Do beta-amyloid (Abeta) deposits in patients with Alzheimer's disease and Down's syndrome grow according to the log-normal model? Neurosci Lett 261(1-2):97100. doi:10.1016/S0304-3940(99)00009-9

2. Blessed G, Tomlinson BE, Roth M (1968) The association between quantitative measures of dementia and of senile change in the cerebral grey matter of elderly subjects. Br J Psychiatry 114:797-811. doi:10.1192/bjp.114.512.797

3. Bolmont T, Haiss F, Eicke D, Radde R, Mathis CA, Klunk WE et al (2008) Dynamics of the microglial/amyloid interaction indicate a role in plaque maintenance. J Neurosci 28(16):42834292. doi:10.1523/JNEUROSCI.4814-07.2008

4. Bolte S, Cordelieres FP (2006) A guided tour into subcellular colocalization analysis in light microscopy. J Microsc 224(Pt 3):213-232. doi:10.1111/j.1365-2818.2006.01706.x

5. Braak H, Braak E (1991) Neuropathological stageing of Alzheimer-related changes. Acta Neuropathol 82(4):239-259. doi: 10.1007/BF00308809

6. Braak H, Braak E (1995) Staging of Alzheimer's disease-related neurofibrillary changes. Neurobiol Aging 16(3):271-284. doi: 10.1016/0197-4580(95)00021-6

7. Braak H, Braak E, Bohl J (1993) Staging of Alzheimer-related cortical destruction. Rev Clin Neurosci 33:403-408

8. Bush A, Beail N (2004) Risk factors for dementia in people with Down syndrome: issues in assessment and diagnosis. Am J Ment Retard 109(2):83-97. doi:10.1352/0895-8017(2004)109<83: RFFDIP $>2.0 . \mathrm{CO} ; 2$

9. Caughey B, Lansbury PT (2003) Protofibrils, pores, fibrils, and neurodegeneration: separating the responsible protein aggregates from the innocent bystanders. Annu Rev Neurosci 26:267-298. doi:10.1146/annurev.neuro.26.010302.081142

10. Cirrito JR, Kang JE, Lee J, Stewart FR, Verges DK, Silverio LM et al (2008) Endocytosis is required for synaptic activity-dependent release of amyloid-beta in vivo. Neuron 58(1):42-51. doi: 10.1016/j.neuron.2008.02.003

11. Corcoran KA, Lu Y, Turner RS, Maren S (2002) Overexpression of hAPPswe impairs rewarded alternation and contextual fear conditioning in a transgenic mouse model of Alzheimer's disease. Learn Mem 9(5):243-252. doi:10.1101/lm.51002

12. Cummings BJ (1997) Plaques and tangles: searching for primary events in a forest of data. Neurobiol Aging 18(4):358-362. doi: 10.1016/S0197-4580(97)00049-3

13. Cummings BJ, Cotman CW (1995) Image analysis of betaamyloid "load" in Alzheimer's disease and relation to dementia severity. Lancet 346:1524-1528. doi:10.1016/S0140-6736(95) 92053-6

14. Cummings BJ, Pike CJ, Shankle R, Cotman CW (1996) Betaamyloid deposition and other measures of neuropathology predict cognitive status in Alzheimer's disease. Neurobiol Aging 17(6):921-933. doi:10.1016/S0197-4580(96)00170-4

15. Cummings BJ, Satou T, Head E, Milgram NW, Cole GM, Savage MJ et al (1996) Diffuse plaques contain C-terminal A beta 42 and not A beta 40: evidence from cats and dogs. Neurobiol Aging 17(4):653-659 
16. Davies CA, Mann DMA (1993) Is the "Preamyloid" of diffuse plaques in Alzheimer's disease really nonfibrillar? Am J Pathol 143(6):1594-1605

17. DeKosky ST, Abrahamson EE, Ciallella JR, Paljug WR, Wisniewski SR, Clark RS et al (2007) Association of increased cortical soluble abeta42 levels with diffuse plaques after severe brain injury in humans. Arch Neurol 64(4):541-544. doi:10.1001/ archneur.64.4.541

18. Deshpande A, Mina E, Glabe C, Busciglio J (2006) Different conformations of amyloid beta induce neurotoxicity by distinct mechanisms in human cortical neurons. J Neurosci 26(22):60116018. doi:10.1523/JNEUROSCI.1189-06.2006

19. Dickson DW (1997) The pathogenesis of senile plaques. J Neuropathol Exp Neurol 56(4):321-339. doi:10.1097/00005072199704000-00001

20. Dickson DW, Crystal HA, Bevona C, Honer W, Vincent I, Davies P (1995) Correlations of synaptic and pathological markers with cognition of the elderly. Neurobiol Aging 16(3):285-304. doi: 10.1016/0197-4580(95)00013-5

21. El Khoury J, Hickman SE, Thomas CA, Cao L, Silverstein SC, Loike JD (1996) Scavenger receptor mediated adhesion of microglia to beta-amyloid fibrils. Nature 382:716-719. doi: $10.1038 / 382716 \mathrm{a} 0$

22. El Khoury J, Hickman SE, Thomas CA, Loike JD, Sliverstein SC (1998) Microglia, scavenger receptors and the pathogenesis of Alzheimer's disease. Neurobiol Aging 19:S81. doi:10.1016/ S0197-4580(98)00036-0

23. Giannakopoulos P, Herrmann FR, Bussiere T, Bouras C, Kovari E, Perl DP et al (2003) Tangle and neuron numbers, but not amyloid load, predict cognitive status in Alzheimer's disease. Neurology 60(9):1495-1500

24. Glabe CG (2006) Common mechanisms of amyloid oligomer pathogenesis in degenerative disease. Neurobiol Aging 27(4):570-575. doi:10.1016/j.neurobiolaging.2005.04.017

25. Glenner GG, Wong CW (1984) Alzheimer's disease and Down's syndrome sharing of a unique cerebrovascular amyloid fibril protein. Biochem Biophys Res Commun 120:885-890. doi: 10.1016/S0006-291X(84)80190-4

26. Gravina SA, Ho L, Eckman CB, Long KE, Otvos L, Younkin LH, Suzuki N, Younkin SG (1995) Amyloid $\beta$-protein (A $\beta$ ) in Alzheimer's disease brain. Biochemical and immunocytochemical analysis with antibodies specific for forms of $A \beta(40)$ and A $342(43)$. J Biol Chem 270:7013-7016. doi:10.1074/jbc.270. 13.7013

27. Hardy J, Selkoe DJ (2002) The amyloid hypothesis of Alzheimer's disease: progress and problems on the road to therapeutics. Science 297(5580):353-356. doi:10.1126/science.1072994

28. Harper JD, Wong SS, Lieber CM, Lansbury PT (1997) Observation of metastable Abeta amyloid protofibrils by atomic force microscopy. Chem Biol 4(2):119-125. doi:10.1016/S1074-5521 (97) $90255-6$

29. Head E, Garzon-Rodriguez W, Johnson JK, Lott IT, Cotman CW, Glabe $C$ (2001) Oxidation of $A \beta$ and plaque biogenesis in Alzheimer's disease and Down syndrome. Neurobiol Dis 8:792806. doi:10.1006/nbdi.2001.0431

30. Hof PR, Bouras C, Perl DP, Sparks DL, Mehta N, Morrison JH (1995) Age-related distribution of neuropathologic changes in the cerebral cortex of patients with Down's syndrome. Arch Neurol 52:379-391

31. Hsaio K, Chapman P, Nilsen S, Eckman C, Harigaya Y, Younkin S, Yang F, Cole G (1996) Correlative memory deficits, Ab elevation, and amyloid plaques in transgenic mice. Science 274:99102. doi:10.1126/science.274.5284.99

32. Iwatsubo T, Mann DM, Odaka A, Suzuki N, Ihara Y (1995) Amyloid beta protein (A beta) deposition: A beta 42(43) precedes
A beta 40 in Down syndrome. Ann Neurol 37(3):294-299. doi: 10.1002/ana.410370305

33. Kang J, Lemaire HG, Unterbeck A, Salbaum JM, Masters CL, Grzeschik KH et al (1987) The precursor of Alzheimer's disease amyloid A4 protein resembles a cell-surface receptor. Nature 325(6106):733-736. doi:10.1038/325733a0

34. Kawarabayashi T, Younkin LH, Saido TC, Shoji M, Ashe KH, Younkin SG (2001) Age-dependent changes in brain, CSF, and plasma amyloid $\beta$ protein in the Tg2576 transgenic mouse model of Alzheimer's disease. J Neurosci 21(2):372-381

35. Kayed R, Head E, Sarsoza F, Saing T, Cotman CW, Necula M et al (2007) Fibril specific, conformation dependent antibodies recognize a generic epitope common to amyloid fibrils and fibrillar oligomers that is absent in prefibrillar oligomers. Mol Neurodegener 2:18. doi:10.1186/1750-1326-2-18

36. Kayed R, Head E, Thompson JL, McIntire TM, Milton SC, Cotman CW et al (2003) Common structure of soluble amyloid oligomers implies common mechanism of pathogenesis. Science 300:486-489. doi:10.1126/science.1079469

37. Khachaturian ZS (1985) Diagnosis of Alzheimer's disease. Arch Neurol 42:1097-1106

38. King DL, Arendash GW, Crawford F, Sterk T, Menendez J, Mullan MJ (1999) Progressive and gender-dependent cognitive impairment in the APP(SW) transgenic mouse model for Alzheimer's disease. Behav Brain Res 103(2):145-162. doi:10.1016/ S0166-4328(99)00037-6

39. Kitamoto T, Ogomori K, Tateishi J, Prusiner SB (1987) Formic acid pretreatment enhances immunostaining of cerebral and systemic amyloids. Lab Invest 57(2):230-236

40. Kumar-Singh S, De Jonghe C, Cruts M, Kleinert R, Wang R, Mercken $M$ et al (2000) Nonfibrillar diffuse amyloid deposition due to a gamma(42)-secretase site mutation points to an essential role for N-truncated A beta(42) in Alzheimer's disease. Hum Mol Genet 9(18):2589-2598. doi:10.1093/hmg/9.18.2589

41. Lai F, Williams MD (1989) A prospective study of Alzheimer disease in Down syndrome. Arch Neurol 46:849-853

42. Lambert MP, Barlow AK, Chromy BA, Edwards C, Freed R, Liosatos $M$ et al (1998) Diffusible, nonfibrillar ligands derived from A $\beta 1-42$ are potent central nervous system neurotoxins. Proc Natl Acad Sci USA 95:6448-6453. doi:10.1073/pnas.95.11.6448

43. Lemere CA, Blusztajn JK, Yamaguchi H, Wisniewski T, Saido TC, Selkoe DJ (1996) Sequence of deposition of heterogeneous amyloid beta-peptides and APOE in Down syndrome: implications for initial events in amyloid plaque formation. Neurobiol Dis 3:16-32. doi:10.1006/nbdi.1996.0003

44. Lesne S, Koh MT, Kotilinek L, Kayed R, Glabe CG, Yang A et al (2006) A specific amyloid-beta protein assembly in the brain impairs memory. Nature 440(7082):352-357. doi:10.1038/ nature 04533

45. Leverenz JB, Raskind MA (1998) Early amyloid deposition in the medial temporal lobe of young Down syndrome patients: a regional quantitative analysis. Exp Neurol 150:296-304. doi: 10.1006/exnr.1997.6777

46. Lott IT, Head E (2001) Down syndrome and Alzheimer's disease: a link between development and aging. Ment Retard Dev Disabil Res Rev 7(3):172-178. doi:10.1002/mrdd.1025

47. Mann DM (1992) Down syndrome and Alzheimer's disease: towards an understanding of pathogenesis. In: Hunter AJ, Clarke S (eds) Neurodegeneration. Academic Press, San Diego, pp 21-31

48. Mann DM, Marcyniuk B, Yates PO, Neary D, Snowden JS (1988) The progression of the pathological changes of Alzheimer's disease in frontal and temporal neocortex examined both at biopsy and at autopsy. Neuropathol Appl Neurobiol 14(3):177195. doi:10.1111/j.1365-2990.1988.tb00880.x 
49. Mann DMA (1988) The pathological association between Down syndrome and Alzheimer disease. Mech Ageing Dev 43:99-136. doi:10.1016/0047-6374(88)90041-3

50. Mann DMA, Esiri MM (1989) The pattern of acquisition of plaques and tangles in the brains of patients under 50 years of age with Down's syndrome. J Neurol Sci 89:169-179. doi:10.1016/ 0022-510X(89)90019-1

51. Masliah E, Terry RD, Mallory M, Alford M, Hansen LA (1990) Diffuse plaques do not accentuate synapse loss in Alzheimer's disease. Am J Pathol 137(6):1293-1297

52. McKee AC, Kosik KS, Kowall NW (1991) Neuritic pathology and dementia in Alzheimer's disease. Ann Neurol 30:156-165. doi:10.1002/ana.410300206

53. Mirra SS, Heyman A, McKeel D, Sumi SM, Crain BJ, Brownlee LM et al (1991) The Consortium to Establish a Registry for Alzheimer's Disease (CERAD). Part II. Standardization of the neuropathologic assessment of Alzheimer's disease. Neurology 41(4):479-486

54. Morgan D, Diamond DM, Gottschall PE, Ugen KE, Dickey C, Hardy J et al (2000) A beta peptide vaccination prevents memory loss in an animal model of Alzheimer's disease. Nature 408(6815):982-985. doi:10.1038/35050116

55. Morris JC, Mohs RC, Rogers H, Fillenbaum G, Heyman A (1988) Consortium to establish a registry for Alzheimer's disease (CERAD) clinical and neuropsychological assessment of Alzheimer's disease. Psychopharmacol Bull 24(4):641-652

56. Morris JC, Storandt M, McKeel DW Jr, Rubin EH, Price JL, Grant EA et al (1996) Cerebral amyloid deposition and diffuse plaques in "normal" aging: evidence for presymptomatic and very mild Alzheimer's disease. Neurology 46(3):707-719

57. Morris JC, Storandt M, Miller JP, McKeel DW, Price JL, Rubin EH et al (2001) Mild cognitive impairment represents early-stage Alzheimer disease. Arch Neurol 58(3):397-405. doi:10.1001/ archneur.58.3.397

58. Nelson PT, Jicha GA, Schmitt FA, Liu H, Davis DG, Mendiondo MS et al (2007) Clinicopathologic correlations in a large Alzheimer disease center autopsy cohort: neuritic plaques and neurofibrillary tangles "do count" when staging disease severity. J Neuropathol Exp Neurol 66(12):1136-1146. doi:10.1097/nen. 0b013e31815c5efb

59. Pallister C, Jung SS, Shaw I, Nalbantoglu J, Gauthier S, Cashman NR (1997) Lymphocyte content of amyloid precursor protein is increased in Down's syndrome and aging. Neurobiol Aging 18(1):97-103. doi:10.1016/S0197-4580(96)00207-2

60. Paresce DM, Chung H, Maxfield FR (1997) Slow degradation of aggregates of the Alzheimer's disease amyloid $\beta$-protein by microglial cells. J Biol Chem 272(46):29390-29397. doi:10.1074/ jbc. 272.46 .29390

61. Paresce DM, Gosh R, Maxfield FR (1996) Microglial cells internalize aggregates of the Alzheimer's disease amyloid $\beta$-protein via a scavenger receptor. Neuron 17:553-565. doi: 10.1016/S0896-6273(00)80187-7

62. Petersen RC, Smith GE, Waring SC, Ivnik RJ, Tangalos EG, Kokmen E (1999) Mild cognitive impairment: clinical characterization and outcome. Arch Neurol 56(3):303-308. doi: 10.1001/archneur.56.3.303

63. Prasher VP, Filer A (1995) Behavioural disturbance in people with Down's syndrome and dementia. J Intellect Disabil Res 39(Pt. 5):432-436
64. Rumble B, Retallack R, Hilbich C, Simms G, Multhaup G, Martins R et al (1989) Amyloid A4 and its precursor in Down's syndrome and Alzheimer's disease. N Engl J Med 320:14461462

65. Schenk D, Barbour R, Dunn W, Gordon G, Grajeda H, Guido T, Hu K, Huang J, Johnson-Wood K, Khan K, Kholodenko D, Lee M, Liao Z, Lieberburg I, Motter R, Mutter L, Soriano F, Shopp G, Vasquez N, Vandervert C, Walker S, Wogulis M, Yednock T, Games D, Seubert P (1999) Immunization with amyloid- $\beta$ attenuates Alzheimer-disease-like pathology in the PDAPP mouse. Nature 400:173-177. doi:10.1038/22124

66. Terry RD, Masliah E, Salmon DP, Butters N, DeTeresa R, Hill R et al (1991) Physical basis of cognitive alterations in Alzheimer's disease: synapse loss is the major correlate of cognitive impairment. Ann Neurol 30(4):572-580. doi:10.1002/ana.410300410

67. The National Institute on Aging aRIWGoDCftNAoAsd (1997) Consensus recommendations for the post mortem diagnosis of Alzheimer's disease. Neurobiol Aging 18(S4):1-2

68. Torp R, Head E, Milgram NW, Hahn F, Ottersen OP, Cotman CW (2000) Ultrastructural evidence of fibrillar $\beta$-amyloid associated with neuronal membranes in behaviorally characterized aged dog brains. Neuroscience 93(3):495-506. doi:10.1016/ S0306-4522(99)00568-0

69. Tyrrell J, Cosgrave M, McCarron M, McPherson J, Calvert J, Kelly A et al (2001) Dementia in people with Down's syndrome. Int J Geriatr Psychiatry 16(12):1168-1174. doi:10.1002/gps.502

70. Walsh DM, Hartley DM, Kusumoto Y, Fezoui Y, Condron MM, Lomakin A et al (1999) Amyloid beta-protein fibrillogenesis. Structure and biological activity of protofibrillar intermediates. J Biol Chem 274(36):25945-25952. doi:10.1074/jbc.274.36.25945

71. Walsh DM, Klyubin I, Fadeeva JV, Cullen WK, Anwyl R, Wolfe MS et al (2002) Naturally secreted oligomers of amyloid beta protein potently inhibit hippocampal long-term potentiation in vivo. Nature 416(6880):535-539. doi:10.1038/416535a

72. Wang B, Larson L (1985) Simultaneous demonstration of multiple antigens by indirect immunofluorescence or immunogold staining. Histochemistry 83:47-56. doi:10.1007/BF00495299

73. Westerman MA, Cooper-Blacketer D, Mariash A, Kotilinek L, Kawarabayashi T, Younkin LH, Carlson GA, Younkin SG, Ashe $\mathrm{KH}$ (2002) The relationship between $\mathrm{A} \beta$ and memory in the Tg2576 mouse model of Alzheimer's disease. J Neurosci 22(5):1858-1867

74. White H (1980) A heteroskedasticity-consistent covariance matrix estimator and a direct test for heteroskedasticity. Econometrica 48:817-830. doi:10.2307/1912934

75. Williams AD, Sega M, Chen M, Kheterpal I, Geva M, Berthelier $\mathrm{V}$ et al (2005) Structural properties of A beta protofibrils stabilized by a small molecule. Proc Natl Acad Sci USA 102(20):7115-7120. doi:10.1073/pnas.0408582102

76. Wisniewski K, Howe J, Williams G, Wisniewski HM (1978) Precocious aging and dementia in patients with Down's syndrome. Biol Psychiatry 13(5):619-627

77. Wisniewski K, Wisniewski H, Wen G (1985) Occurrence of neuropathological changes and dementia of Alzheimer's disease in Down's syndrome. Ann Neurol 17:278-282. doi:10.1002/ana. 410170310 